\title{
Dificuldade diagnóstica em dois casos de neoplasia de células linfóides precursoras cutâneas primárias
}

\section{Diagnostic pitfalls in two cases of primary cutaneous neoplasia of precursor lymphocytes}

Cláudia Regina Gomes Cardim Mendes de Oliveira'; Daniel Chang²; Denise Aratangy Arnaut de Mello Lula3; Carlos Fernando Saito ${ }^{4}$; Maria Cláudia Nogueira Zerbini ${ }^{5}$

\section{unitermos}

Linfoma primário cutâneo

Linfoma linfoblástico

Linfoma não-Hodgkin

Linfoma linfoblástico de

células NK-símile

\section{resumo}

O linfoma linfoblástico (LLB) é uma neoplasia maligna de linfócitos precursores ( $B, T$ ou células NK). $O$ comprometimento primário da pele é raro. Relatamos as características clínicas, anatomopatológicas e imunofenotípicas em dois pacientes com apresentação cutânea primária que, histologicamente, apresentavam infiltrado de células imaturas. A análise imunofenotípica foi realizada com amplo painel de anticorpos. A pesquisa de rearranjo no gene do receptor de células T (TCR-gama) pelo método de reação em cadeia da polimerase (PCR) resultou positiva em um caso, que era CD56 positivo, classificado como linfoma de células NK blásticas-símile. Este caso representa uma entidade distinta derivada de células precursoras num estágio precoce de uma via comum de diferenciação para células T e NK. O outro caso foi classificado como LLB-T com expressão aberrante de CD79a, o que poderia ser erroneamente interpretado. O diagnóstico correto depende da utilização de um amplo painel de anticorpos para caracterização imunofenotípica e avaliação molecular.

\section{abstract}

The lymphoblastic lymphoma (LBL) is a malignant neoplasm of precursor lymphocytes ( $B, T$ or NK-cells). The primary involvement of the skin is rare. We examined the clinical, anatomopathological and immunophenotypic features of two patients with primary cutaneous involvement. Histologically they showed an infiltrate of immature cells. The immunophenotypic analysis was performed with a comprehensive panel of antibodies. T-cell receptor rearrangement (TCR-gamma) was analyzed with polymerase chain reaction $(P C R)$ and it was positive in one case, which was CD56 positive, classified as blastic NK-cell-like lymphoma. This case represents a distinct entity derived from precursor cells at an early stage of a common developmental pathway for $T$ and NK cells. The other case was classified as T-cell lymphoblastic lymphoma with aberrant expression of $C D 79 a$, what could be a diagnostic pitfall. The accurate diagnosis depends on the use of a comprehensive panel of antibodies for immunophenotypic characterization and molecular analysis. key words

Primary cutaneous

lymphoma

Lymphoblastic lymphoma

Non-Hodgkin's lymphoma

Blastic NK-cell-like

lymphoma

\footnotetext{
1. Doutora em Medicina; assessora médica de Anatomia Patológica e Citopatologia do Fleury Medicina e Saúde; médica chefe do Setor de Anatomia Patológica do Instituto de Ortopedia e Traumatologia do Hospital das Clínicas da Faculdade de Medicina da Universidade de São Paulo (IOT/HCFMUSP).

2. Mestre em Medicina; assessor médico de Anatomia Patológica e Citopatologia do Fleury Medicina e Saúde.

3. Bióloga; assessora técnica de Anatomia Patológica e Citopatologia do Fleury Medicina e Saúde.

4. Biomédico; analista laboratorial de Anatomia Patológica e Citopatologia do Fleury Medicina e Saúde.

5. Doutora em Medicina; assessora médica de Anatomia Patológica e Citopatologia do Fleury Medicina e Saúde; professora doutora do Departamento de Anatomia Patológica da FMUSP.

Trabalho realizado no Fleury Medicina e Saúde e apresentado no XXV Congresso Brasileiro de Patologia, Natal-RN, de 12 a 15 de outubro de 2005.
} 


\section{Introdução}

Na classificação atual para linfomas primários cutâneos da Organização Mundial da Saúde (OMS) e da World Health Organization/European Organization of Research and Treatment of Cancer (EORTC) ${ }^{(14)}$, o linfoma de células NK-blásticas foi reclassificado como uma neoplasia hematológica de células precursoras associada à evolução clínica agressiva ${ }^{(1,4,6,8)}$. Linfomas primários cutâneos de células precursoras são extremamente raros, sendo muitas vezes difícil a definição de sua linhagem histogenética, incluindo as possibilidades de linhagem B, T e NK ${ }^{(10-12)}$. A manifestação cutânea da doença mais freqüentemente é secundária e segue de comprometimento da medula óssea (MO) e sangue periférico (SP), mas pode, em alguns casos, permanecer por algum tempo confinada à pele ${ }^{(5)}$. Caracteriza-se por apresentar morfologia e imunofenótipo de célula imatura ou blástica, com expressão de CD56, o que sugere inicialmente origem em célula NK precursora. Recentemente alguns estudos têm demonstrado que a neoplasia deriva de um precursor de célula dendrítica plasmocitóide, sendo por isso classificada como neoplasia hematodérmica CD4 positivo/CD56 positivo(9, 12).

O objetivo deste trabalho é apresentar dois casos raros de linfomas de células precursoras com manifestação cutânea primária e características clínicas e imunofenotípicas incomuns, ilustrando a dificuldade em se caracterizar a célula de origem, tornando-se obrigatória a utilização de amplo painel para caracterização imunofenotípica e avaliação molecular na tentativa de se definir a linhagem dessas neoplasias.

\section{Relato dos casos}

\section{Caso 1}

Paciente do sexo masculino, 11 meses de idade, com nódulo cutâneo isolado de crescimento progressivo (medindo $2,5 \mathrm{~cm}$ de diâmetro) em região frontal de couro cabeludo. Realizou-se biópsia incisional da lesão com punch. O material apresentava-se esbranquiçado e de consistência elástica, sendo totalmente submetido a processamento histológico rotineiro para inclusão em parafina e coloração por hematoxilina e eosina (HE). À microscopia ótica mostrava uma população difusa e monótona de células de médio tamanho, de aspecto imaturo, com freqüentes figuras mitóticas e macrófagos com aspecto de céu estrelado (Figura 1). A epiderme estava preservada. O imunofenótipo avaliado por imuno-histoquímica revelou positividade para CD45 (clone
2B11+PD7/26, 1:4000 - Dakocytomation, Carpenteria, CA, EUA), CD79a (clone 11E3, 1:200 - Novocastra, Newcastle, UK), CD3 (clone F7.2.38, 1:100 - Dakocytomation, Carpenteria, CA, EUA), CD5 (clone CD5/54/F6, 1:100 - Dakocytomation, Carpenteria, CA, EUA), CD43 (clone DF-T1, 1:200 - Dakocytomation, Carpenteria, CA, EUA), CD99 (clone 12E7, 1:800 - Dakocytomation, Carpenteria, CA, EUA), TdT (policlonal, 1:20 - Dakocytomation, Carpenteria, CA, EUA) e Ki67 (50\%) (clone KI-S5, 1:200 - Dakocytomation, Carpenteria, CA, EUA) (Figuras 2, 3 e 4), sendo negativos os marcadores mielóides, linfóides B e NK. A neoplasia foi classificada como de célula hematológica precursora ou linfoma linfoblástico T (LLB-T), apresentando rápida evolução para envolvimento de MO e SP. O estudo de biologia molecular para a pesquisa do rearranjo de receptor de células $T$ não foi realizado neste caso, visto que o material foi praticamente todo utilizado na confecção dos cortes histológicos e do estudo imuno-histoquímico.

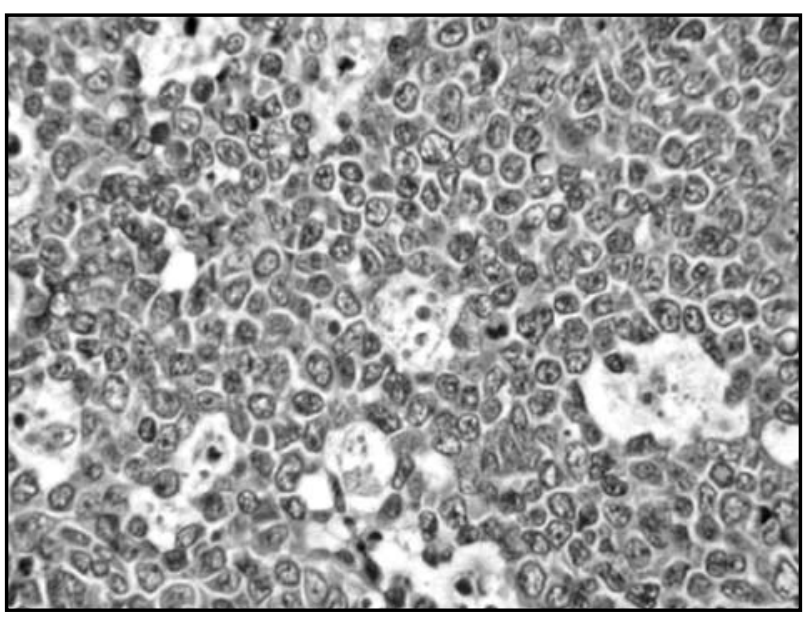

Figura 1 (caso 1) - População de células imaturas com macrófagos de permeio caracterizando o aspecto de céu estrelado (HE, 400x)

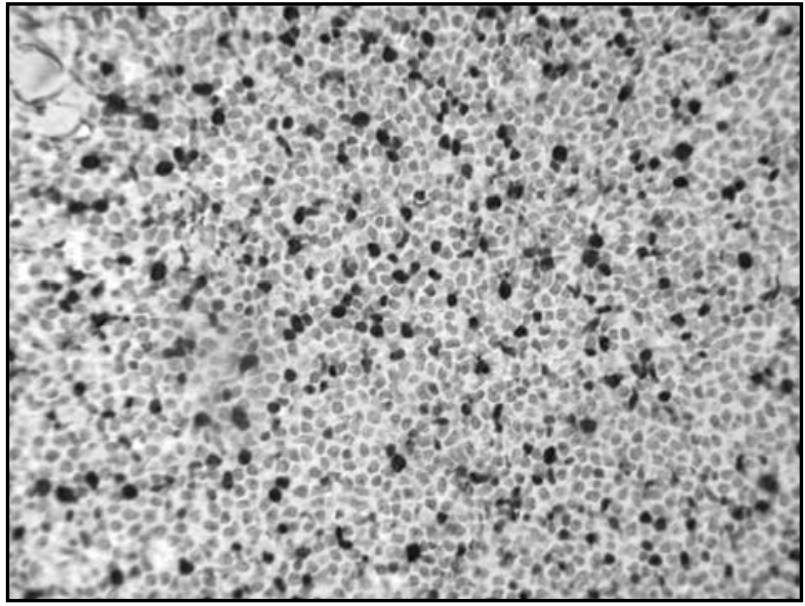

Figura 2 (caso 1) - Imunorreatividade nos núcleos de células neoplásicas para $\operatorname{TdT}(100 x)$ 


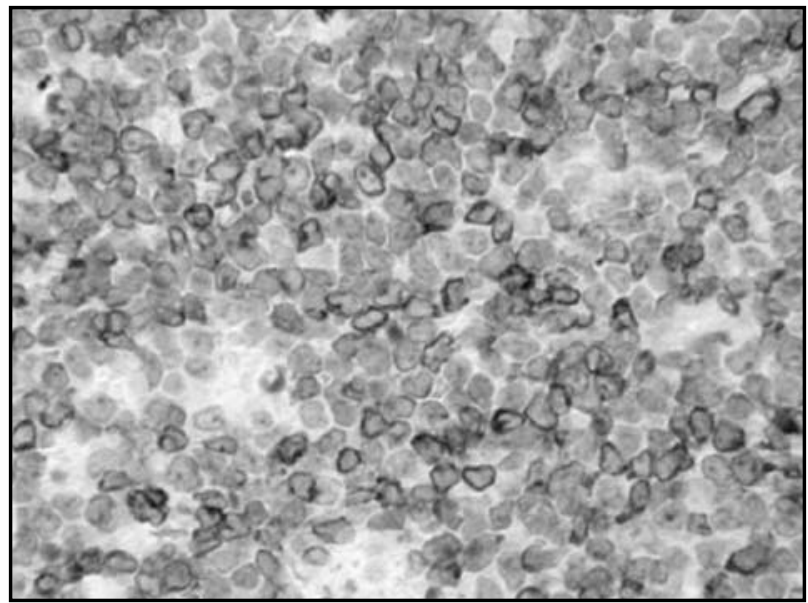

Figura 3 (caso 1) - Imunorreatividade nas membranas celulares de células neoplásicas para CD79a (400x)

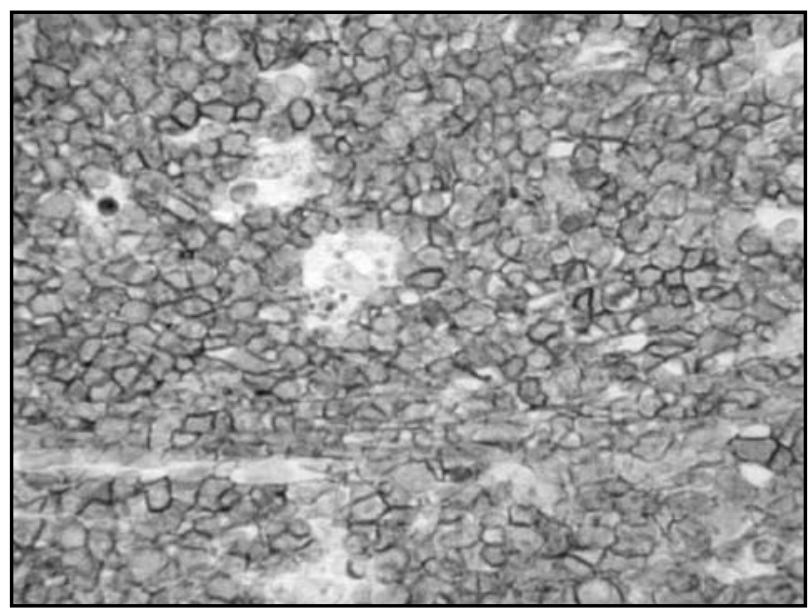

Figura 4 (caso 1) - Imunorreatividade nas membranas celulares de células neoplá sicas para CD3 (400x)

\section{Caso 2}

Paciente de sexo feminino, 53 anos, com nódulo cutâneo isolado (medindo $1 \times 0,8 \times 0,8 \mathrm{~cm}$ ) em antebraço direito surgido há três meses com crescimento progressivo. A lesão foi completamente excisada e apresentava, aos cortes, consistência elástica e coloração esbranquiçada. Todo o material foi submetido a processamento histológico rotineiro para inclusão em parafina e coloração por HE. A análise microscópica exibia uma população difusa e monótona de células de tamanho intermediário, cromatina irregularmente distribuída e com freqüentes figuras mitóticas (Figura 5). A epiderme não estava envolvida. O estudo imuno-histoquímico mostrou positividade para CD45, S-100 (policlonal, 1:3000 - Dakocytomation, Carpenteria, CA, EUA), TdT, CD56 (clone 1B6, 1:20 - Novocastra, Newcastle, UK) (Figura 6), CD43, HLA-Dr, CD7 (clone 272, 1:50 - Novocastra, Newcastle, UK) e Ki67 (60\%); a pesquisa para os demais marcadores, ou seja, de células mielomonocíticas (CD 68/clone KP1, 1:1000 - Dakocytomation, Carpenteria, CA, EUA e CD117/policlonal, 1:350, Dakocytomation, Carpenteria, CA, EUA), T (CD3 e CD4/clone 4B12, 1:400, Novocastra, Newcastle, UK) e B (CD20/clone L26, 1:400 - Dakocytomation, Carpenteria, $C A, E U A)$ resultou negativa.

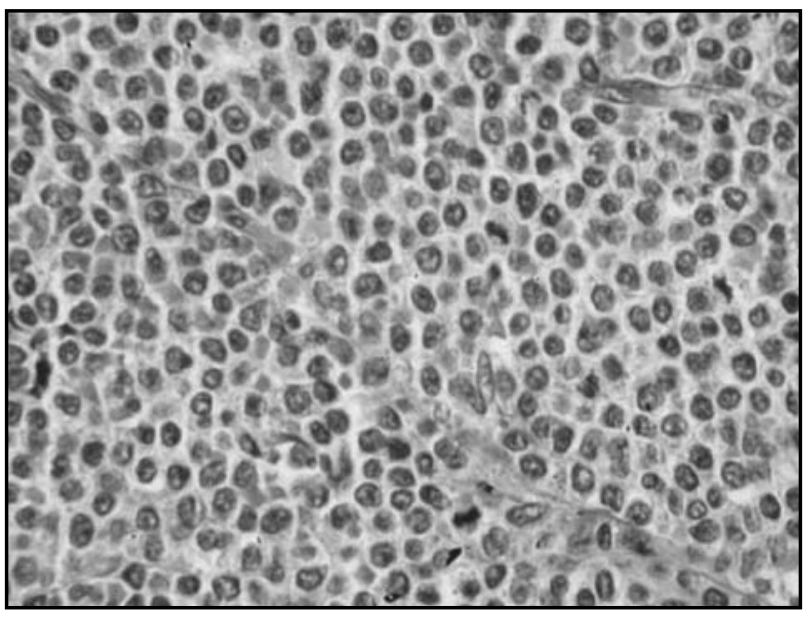

Figura 5 (caso 2) - População de células de tamanho intermediário com freqüentes figuras mitóticas (HE, 400x)

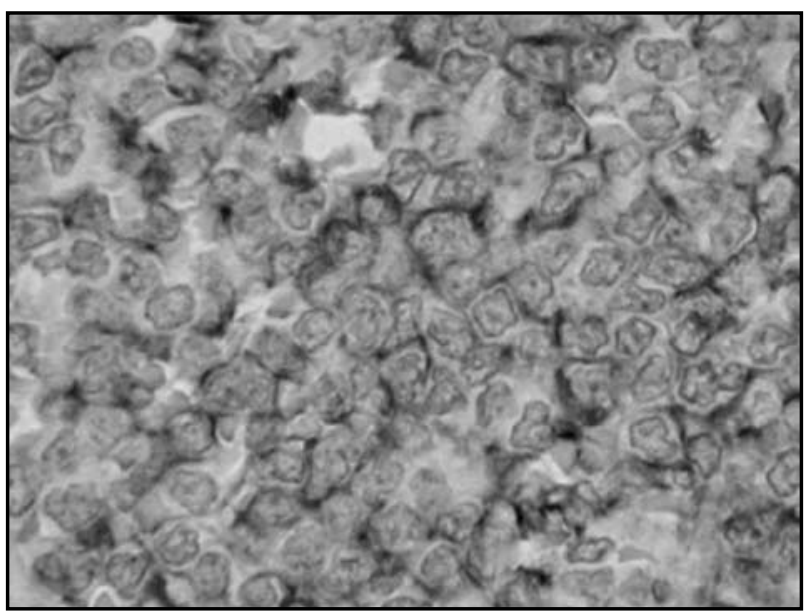

Figura 6 (caso 2) - Imunorreatividade nas membranas celulares de células neoplásicas para CD56 (800x)

Concluiu-se como neoplasia de célula hematológica precursora/neoplasia hematodérmica CD56+ (linfoma cutâneo de células NK blásticas) (OMS/EORTC, 2005). Entretanto, a pesquisa de rearranjo para o gene do receptor da célula T (TCR) por PCR foi positiva, excluindo a possibilidade de células NK verdadeiras, apesar da positividade para CD56. Esse achado molecular, associado ao perfil de uma célula primitiva (TdT positiva), com expressão de CD56 e ausência da imunoexpressão de marcadores específicos de imunofenótipo T, leva-nos a classificar a 
lesão como linfoma de células blásticas NK-símiles, com rearranjo para o receptor da célula $T^{(7)}$. A revisão da literatura ilustra raros casos semelhantes, sendo classificados como linfoma de células blásticas NK-símile, com rearranjo para o gene do receptor da célula $T^{(7,16)}$. Por fim, não foi detectada doença em nenhum outro sítio, além do inicialmente diagnosticado, sem evidências de infiltração nodal ou da MO.

\section{Discussão}

\section{Caso 1}

O LLB deriva de uma proliferação clonal de células precursoras linfóides ${ }^{(1,4)}$. A caracterização do imunofenótipo é importante para o prognóstico, e a apresentação cutânea primária é extremamente rara no $\operatorname{LLB}-T^{(5,13,14)}$, sendo a maioria desses casos classificada como LLB-B, ocorrendo na faixa etária pediátrica. A expressão para CD3 e CD43 no caso estudado demonstrou imunofenótipo T. Entretanto, cerca de $10 \%$ dos casos de LLB-T com CD3 positivo e CD20 negativo têm mostrado expressão aberrante de CD79a, conforme observado neste caso $^{(8,15,16)}$. O CD79a é um marcador associado à imunoglobulina de superfície do complexo receptor de antígeno de células linfóides $B$, expresso por uma subpopulação de células $B$ e plasmócitos, sendo um dos mais importantes marcadores para a linhagem de células B. Expressão aberrante de CD79a tem sido relatada em células neoplásicas nos linfomas $T$ periféricos, leucemia mielóide aguda (M3), especialmente com translocação $\mathrm{t}(8 ; 21)$, em cerca de $10 \%$ dos casos de linfomas $T$ de células precursoras ${ }^{(2)}$, e também em precursores eritróides na $\mathrm{MO}^{(3)}$. Isso se relaciona com o fato de que nenhum marcador tem absoluta especificidade e a infidelidade de linhagem é mais freqüente em células linfóides precursoras e mielóides. Aliás, a fidelidade de linhagem é geralmente a regra em neoplasias de células $T$ e $B$ maduras.

O presente caso ilustra a complexidade de classificação da linhagem nos linfomas, necessitando-se da análise imunofenotípica com amplo painel de anticorpos. Casos com fenótipo aberrante podem necessitar de estudos genotípicos. A aberrante expressão de antígenos associados às células
B é infreqüente ${ }^{(15)}$, todavia pode ocasionar interpretação diagnóstica incorreta.

\section{Caso 2}

A neoplasia hematodérmica CD4+/CD56+ ou linfoma cutâneo de células NK blásticas está definida pela OMS/ EORTC como uma entidade clinicopatológica distinta caracterizada por tropismo pela pele, envolvimento da medula óssea e curso clínico agressivo, com imunofenótipo compatível com células NK (CD4+/CD56+/CD43+/ $\mathrm{HLA}-\mathrm{DR}+$ ) e negatividade para o rearranjo do gene dos receptores da célula $T^{(12,15,16)}$. Raros casos de linfomas cutâneos primários de linhagem imatura não-B e não-T CD56 positivo com características morfológicas e imunofenotípicas superponíveis ao linfoma cutâneo de células NK blásticas têm sido recentemente descritos como entidades distintas em que a origem das células neoplásicas não está totalmente esclarecida, sendo postulada inclusive a possibilidade de origem em células dendríticas plasmocitóides ou monócitos plasmocitóides ${ }^{(9,12)}$. A análise molecular nestes casos revela o rearranjo do gene TCR, como se observou em nosso caso. Uma hipótese aventada é a de que essas células teriam origem num estágio precoce de uma via comum de diferenciação para células T e NK. A diferença entre o presente caso e os relatos da literatura é o achado do intrigante imunofenótipo CD4-/S100+. Os marcadores mielomonocíticos CD68 e CD117 foram negativos, o que vai contra a origem em precursor mielomonocítico. A positividade para o HLA-Dr pode ser evidenciada em células T em estágio precoce de diferenciação e também em linfomas de células NK-blásticas ${ }^{(7,16)}$.

\section{Conclusão}

Apresentamos aqui dois casos de neoplasia hematológica de células precursoras, com localização primária na pele, absolutamente incomuns. Um deles classificado como linfoma de células NK blásticas-símiles com rearranjo para o gene TCR e o outro, uma rara apresentação cutânea primária de um linfoma linfoblástico $T$ em paciente pediátrico. Esses casos ilustram a importância de estudo imunoistoquímico com amplo painel de anticorpos e da avaliação molecular para a caracterização dessas neoplasias. 


\section{Referências}

1. AOYAMA, Y. et al. Blastic NK-cell lymphoma/leukemia with T-cell receptor $\gamma$ rearrangement. Ann Hematol, v. 80, p. 752-4, 2001.

2. FLORA, R. S. et al. Aberrant positivity for CD79a in erythroid lineage cells: a finding observed in a subset of. restaging bone marrow trephine biopsies after treatment. Haematologica, v. 92, p. 855-6, 2007.

3. HASHIMOTO, M. et al. Immunohistochemistry detection of CD79a expression in precursor T cell lymphoblastic lymphoma-leukaemias. The Journal of Pathology, v. 197, p. 341-77, 2002.

4. KARUBE, K. Non-B, non-T neoplasma with lymphoblast morphology: further classification. Am J Surg Pathol, v. 27, n. 10, p. 1366-74, 2003.

5. LIN, P. et al. Precursor B-cell lymphoblastic Iymphoma: a predominantly extranodal tumor with low propensity leukemic involvement. Am J Surg Pathol, v. 24, p. 1480-90, 2000.

6. LIU, X. Y. et al. Blastic NK-cell-like lymphoma with T-cell receptor gene rearrangement. Am J Hematol, v. 75, p. 251-3, 2004.

7. MILLOT, F. Cutaneus involvement in children with acute lymphoblastic leukemia or lymphoblastic lymphoma. The Children's Leukemia Cooperative Group of the European Organization of Research and Treatment of Cancer (EORTC). Pediatrics, v. 100, p. 60-4, 1997.

8. MOMOE, A. Cutaneous lymphoblastic lymphoma of postulated plasmacytoid dendritic cell-precursor origin: two cases. Leuk Res, v. 26, n. 7, p. 693-8, 2002.

9. OHSHIMA, K. et al. The World Health Organization classification of malignant lymphoma: incidence and clinical prognosis in HTLV-1 endemic area of Fukuoka. Pathol Int, v. 52, n. 1, p. 1-12, 2002.

10. PARLETTE, E. C. et al. Primary cutaneous blastic natural killer cell lymphoma. J Am Acad Dermatol, v. 53, n. 4, p. 742-3, 2005.

11. PETRELLA, T. et al. Agranular CD4/CD56 hematodermic neoplasm (blastic NK-cell lymphoma) originates from a population of CD56 precursor cells related to plasmacytoid monocytes. Am J Surg Pathol, v. 26, p. 852-62, 2002.

12. SLATER, D. N. The new World Health Organization classification of haematopoietic and lymphoid tumours: a dermatopathological perspective. British Journal of Dermatology, v. 147, p. 633-9, 2002.

13. WILENT, S. E. Blastic natural killer-cell lymphoma: a case report. Cutis, v. 77, n. 1, p. 42-4, 2006.

14. WILLENZE, R. etal. WHO/EORTC classification for cutaneous lymphomas. Blood, v. 105, n. 10, p. 3768-85, 2005.

15. XU, Y. et al. Peripheral T-cell lymphoma with aberrant expression of CD79a and CD20. A diagnostic pit fall. Mod Pathol, v. 14, n. 12, p. 105-10, 2001.

16. ZHANG, K. et al. Blastic natural killer (NK) cell leukemia (agranular CD4 + CD56 +). Ann Clin Lab Sci, v. 36, n.2, p. 212-5, 2006. 